\title{
Cranial Gunshot Injury in a Child
}

\author{
Dimitrios Panagopoulos, George A Alexiou*, Dimosthenis Kipriotis and Neofytos Prodromou
}

Department of Neurosurgery, Children's Hospital '’Agia Sofia', Athens, Greece

\begin{abstract}
We present a cases of a cranial gunshot injury in a 8-year-old girl. Brain computed tomography demonstrated a depressed skull fracture with an underlying cerebral contusion. The patient was operated upon and debridement of the wound was performed. A craniectomy was then performed around the skull fracture, the dura was opened and the subdural hematoma with the cerebral contusion were removed. Four months later a cranioplasty was performed. On followup examination one year later the patient was in excellent condition.
\end{abstract}

Keywords: Children, gunshot, head trauma.

An 8-year-old girl arrived in the emergency department after a gunshot wound on the head. The patient presented with an initial Glasgow coma scale score of 11. Clinical examination showed a left parietal ragged laceration. A brain CT was performed and demonstrated a depressed skull fracture with an underlying cerebral contusion. The patient was

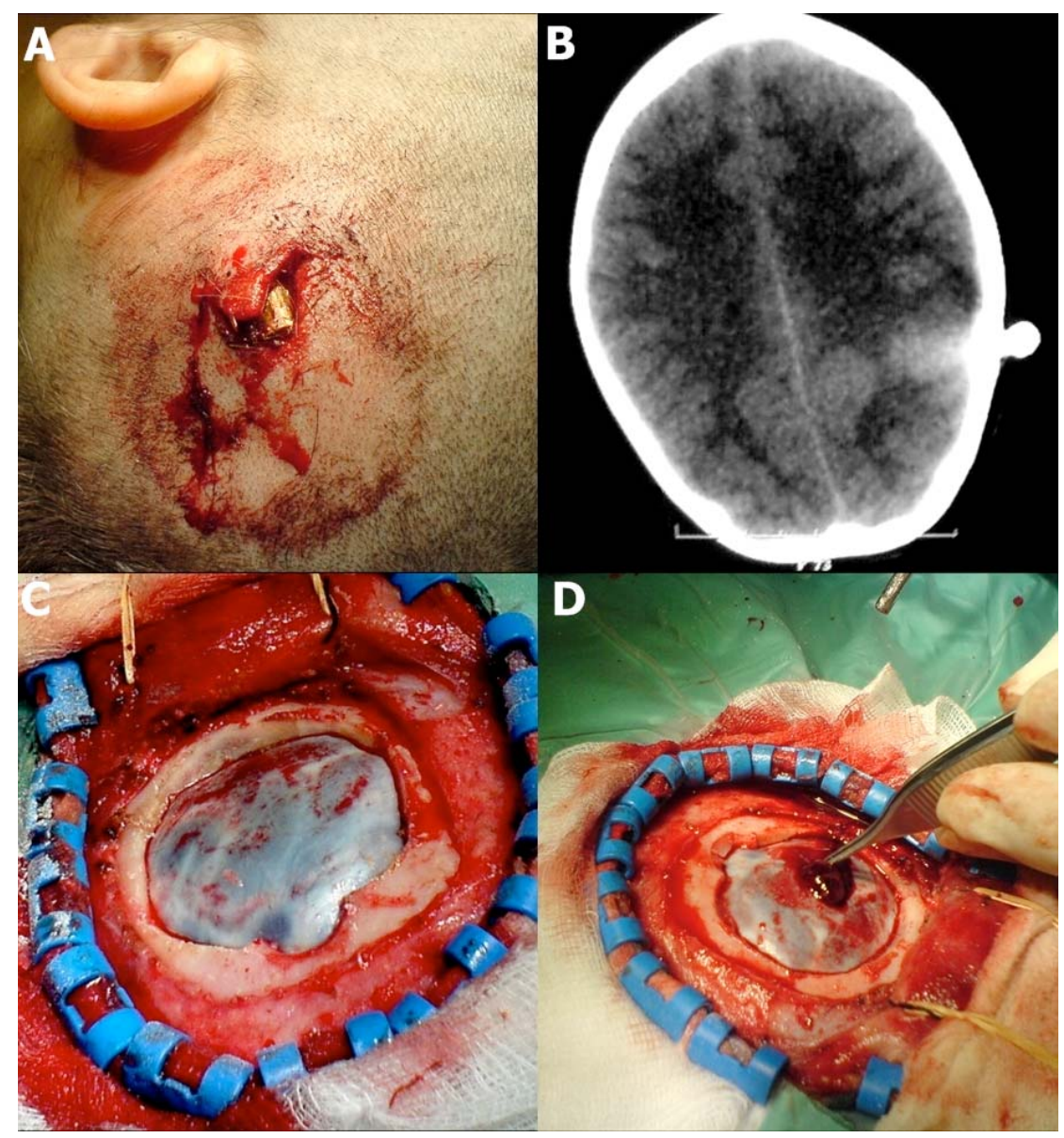

Fig. (1). A. Preoperative photograph showing the gunshot wound. B. Axial CT scan revealing the bullet. C. Craniectomy. The dura matter was intact. D. Dura incision and hematoma evacuation.

*Address correspondence to this author at the Aetideon 52, Holargos, Attikis, 11561, Greece; Tel: +30 210 6526507, +30 6948 525134; Fax: +30 2107467014 ; E-mail: alexiougrg@yahoo.gr,alexiougr@gmail.com urgently brought to the operating room and debridement of the wound was performed. A craniectomy was then performed around the skull fracture, the dura was opened and the subdural hematoma with the cerebral contusion were 


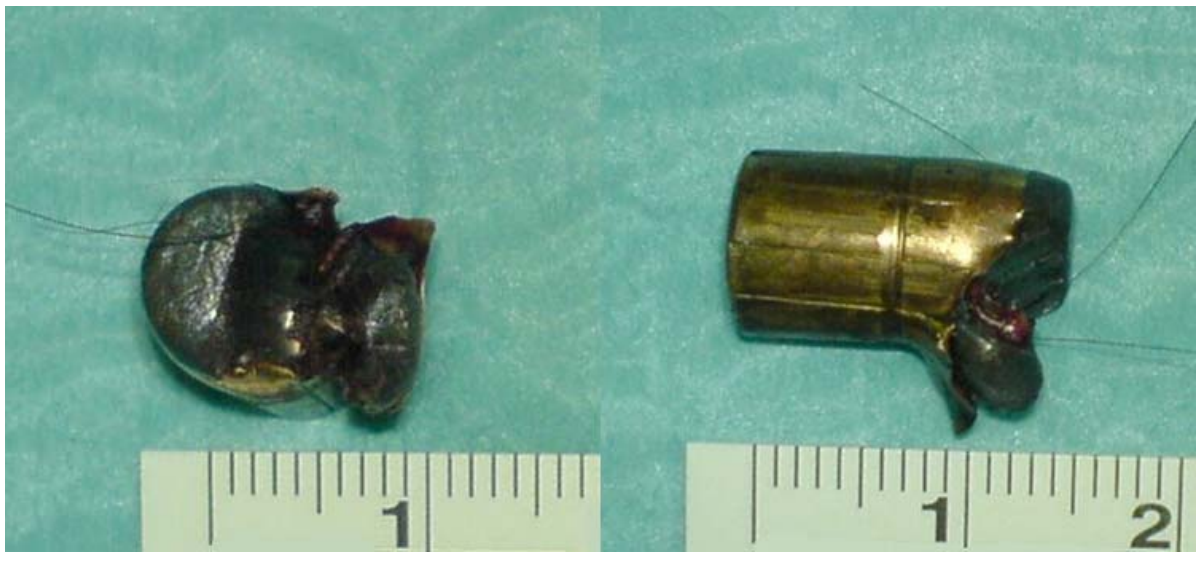

Fig. (2). Fragments of the bullet.

removed (Figs. 1, 2). Careful hemostasis was established, the dura was closed watertight with a periosteum graft and high doses of wide-spectrum antibiotics were administered. Postoperative the patient had no neurological deficits or seizures. Four months later a cranioplasty was performed. On followup examination one year later the patient was in excellent condition.

Although rare, gunshot wounds are the most frequent penetrating head injuries and are frequently associated with high morbidity and mortality. Bihemispheric is the most common injury pattern in these cases [1]. The majority of victims are boys. Patients that survive usually have several neurological deficits [2]. Nevertheless, few patients that present in a good neurological state may have a better outcome [3]. For these cases surgery and extensive debridement should be performed as soon as possible $[4,5]$. In the present case the patient was treated surgically immediately upon admission and careful debridement was performed. Thus, apart from the neurological status upon emergency room arrival, early aggressive management may improve outcome.

\section{REFERENCES}

[1] Irfan FB, Hassan RU, Kumar R, Bhutta ZA, Bari E. Craniocerebral gunshot injuries in preschoolers. Childs Nerv Syst 2010; 26: 61-6.

[2] Rosenfeld JV. Gunshot injury to the head and spine. J Clin Neurosci 2002; 9: 9-16.

[3] Levy ML. Outcome prediction following penetrating craniocerebral injury in a civilian population: aggressive surgical management in patients with admission Glasgow Coma Scale scores of 6 to 15 . Neurosurg Focus 2000; 8: e2.

[4] Martins RS, Siqueira MG, Santos MT, et al. Prognostic factors and treatment of penetrating gunshot wounds to the head. Surg Neurol 2003; 60: 98-104.

[5] Alexiou GA, Sfakianos G, Prodromou N. Head trauma in children. J Emerg Trauma Shock (in press).

Received: April 01, 2011

(C) Panagopoulos et al.; Licensee Bentham Open.

This is an open access article licensed under the terms of the Creative Commons Attribution Non-Commercial License (http://creativecommons.org/licenses/by-nc/3.0/) which permits unrestricted, non-commercial use, distribution and reproduction in any medium, provided the work is properly cited. 